\title{
REFLEXÕES DO PENSAMENTO DE JOHN RAWLS NA OBRA O DIREITO DOS POVOS
}

\author{
REFLECTIONS ON JOHN RAWLS' THOUGHT IN THE WORK THE LAW OF PEOPLES
}

Maria José Galleno de Souza Oliveira

\begin{abstract}
Resumo:
O texto é uma reflexão sobre a obra de John Rawls "O direito dos povos" Apresenta sinteticamente alguns pressupostos éticos-politicos desenvolvidos por Rawls ao longo da sua vida. É a proposta sobre a possibilidade dos povos se unirem e caminharem em direção de uma Sociedade dos povos, fundamentada sobre os princípios de justiça e respeito à liberdade.
\end{abstract}

Palavras-chave: Direito dos povos. Teoria da justiça. Pluralismo razoável. Racionalidade. Utilitarismo. Véu da ignorância. Sociedade bem ordenada. Liberalismo político.

Abstract:

This text is a reflection on the John Rawls' work "The Law of the Peoples" It presents briefly some ethical-political assertions developed by Rawls in his life. The purpose of the possibility of people to join and to step toward a people society, based on justice principles and freedom observance.

Keywords: Law of Peoples. Theory of Justice. Reasonable Pluralism. Rationality. Utlitarism. Ignorance Veil. Well-Ordered Society. Political Liberalism.

1. Algumas considerações gerais

1.1. O autor John Rawls

Nasceu na cidade de Baltimore. Maryland, nos Estados Unidos da América (1921). Doutorou-se em Filosofia e Letras na Universidade de Princeton (1950), na qual iniciou sua carreira acadêmica. Foi professor da Universidade de Cornell e da Universidade de Harvard (1962). Mas, foi nesta última que foi nomeado University Professor, título das mais altas congratulações acadêmicas. alcançadas por muito poucos professores. Em Harvard, ocupou a cadeira de Filosofia Moral, disciplina que compreende as temáticas de Ética, Política e Direito nos paises de lingua inglesa.

Conferencista dos mais distintos em Universidades dos Estados Unidos e outros países, especialmente Europa, elaborou suas obras a partir de suas conferências e de seus artigos publicados em revistas de Filosofia, Política e Direito.

Professora Assistente do Departamento de Filosofia e Teoria Geral do Direlto da Faculdade de Direito da Universidade de Sãu Paulu. 
Exímio conhecedor do pensamento clássico, principalmente Platão e Aristóteles, não se dedicou aos estudos do pensamento cristão. Uma de suas fontes principais de inspiração filosófica foram os pensamentos de Thomas Hobbes, John Locke, David Hume. Mas, dedicou-se com maior atenção a Kant ( $A$ Critica da Razão Prática, A Metafisica dos Costumes e outros escritos), Jeremias Bentham (Teoria do Utilitarismo - O fím a buscar é a maior felicidade do maior número, entendida como a soma dos prazeres e das dores dos indivíduos) e John Stuart Mill (tradição empirista do pensamento inglês).

Devido ao seu contexto histórico-cultural, Rawls está incluído dentro do liberalismo clássico e do utilitarismo.' Mas, também se encontra nas suas obras, influencias do existencialismo, marxismo e da filosofia analítica. ${ }^{2}$

Rawls não se preocupava em discutir as posições filosóficas, morais e religiosas, quer fossem próximas ou distantes da sua tradição cultural. Para ele, o que interessava era se havia o consenso entre os membros da sociedade. tendo por base a liberdade e a igualdade das pessoas (objetivo fundamental de seus trabalhos).

Por tudo isso, Rawls é um dos autores mais importantes para o estudo da Filosofia (especialmente a Filosofía Política) no Direito e na Política. Pode-se dizer, reproduzindo Robert Nozick que "agora os filósofos politicos terão de trabalhar segundo a teoria de Rawls, ou explicar porque não o fazem" O que no entender de Rubio Carrecedo, as obras de Rawls são tão completas e elaboradas, ricas em matizes e distinções, que se constituem em uma nova suma de conhecimentos morais, econômicos, sociais, psicológicos, filosóficos e epistemológicos; tudo balizado em um enfoque liberal social.

Ralws morreu aos 24 de novembro de 2002.

O liberalismo que estuda o pluralismo, vislumbram a possibilidade de uma elaboração e fundamentação de um idcal de justiça, sendo que o Direito é vislumbrado como elemento de consecuçào de seus objetivos. pois é garantidor da neutralidade estatal. O fundamento deste Direito é dado através do papel atribuido ao sistema de direitos c garantias pela Constituição. A interpretação desta Constituição deve se pautar pelos principios e normas, entendendo o Direito como prioritärio sobre quaisquer das concepçōes de bem. $\dot{A}$ mesma Constituição cabe a função de garantir liberdades negativas assecuratorias da autonomia moral individual. Os dois grandes pilares do pensamento liberal são os norte-americanos Ronald Dworki e John Rawls.

- Corrente do pensamento dominante dos paises de língua inglesa, a qual busca as precisūes lingüisticas, rechaçando toda a influência de ordem metafisica. 


\subsection{Principais Obras de John Rawls}

Os principais livros publicados por Rawls, são: Uma Teoria da Justiça, A Justiça como Equidade, A Justiça como Imparcialidade, Sobre a Liberdade, Liberalismo Político, O Direito dos Povos (1993).

Alguns artigos de Rawls, que orientaram seus livros, são: Plano para um procedimento de decisão ética (1951), Dos Conceitos de Regras (1951 primeiro esboço de sua teoria ética), Justiça como Imparcialidade (versões e modificações -1957, 1958, 1961 e 1962), Liberdade Constitucional e o Conceito de Justiça (1963), A Obrigação Legal e o Jogo Honrado (1963), Justiça Distributiva (1967 e 1968), A Justificativa da Desobediência Civil (1969), A Independência da Teoria Moral (1975), A Estrutura Básica do Sujeito (1977), O Construtivismo Kantiano na Teoria Moral (1980), As Liberdades Básicas e suas Prioridades (1982 e 1987), Justiça Distributiva (1980), A Prioridade do Direito e a Idéia do Bom (1988).

É importante frisar que, em 1980, Rawls realizou uma revisão de sua obra fundamental - Uma Teoria da Justiça - para melhor precisar seus conceitos sobre bens primários, racionalidade, razoabilidade, o bem e o justo, as diferenças entre o modelo liberal-radical e o liberal-social. Sendo que, em 1985, novamente realizou outra revisão nesta obra, com a finalidade de deixar bem evidente o caráter político de justiça. afastando por completo toda e qualquer idéia que transparecesse sobre elementos metafísicos na obras.

A produção científica de Rawls foi toda escrita em inglês. Mas, grande parte dessa produção foi traduzida para o português, espanhol, francês, alemão, italiano, russo e holandês.

\section{Aspectos gerais sobre o livro "O Direito dos Povos"}

Nessa obra, Rawls procura validar um padrão de eqüidade entre os povos a partir de um sistema de cooperação mútua. semelhante ao caso interno, que permita que eles alcancem um nível de qualidade de vida para os seus cidadãos, de acordo com uma concepção de justiça política razoável e com o pluralismo razoável.

A tese mais fortemente defendida por Rawls para a configuração desta Sociedade dos Povos remonta a teoria da paz perpétua de Kant, que já imaginava em seu tempo, nos idos do século XVIII, ser possível verificar um ambiente internacional de paz entre os Estados constituídos por uma confederação de repúblicas. As repúblicas kantianas são agora as atuais democracias constitucionais liberais rawlsianas. E, também busca subsídios na idéia kantiana de foedus pacificum (federação pacífica). 
$\mathrm{Na}$ introdução, Rawls esclarece que utilizará os conceitos de justiça como eqüidade desenvolvida na obra Uma Teoria da Justiça de um lado, e; por outro lado, os conceitos de Direito político da obra Liberalismo Político. Enfatiza que "o Direito dos Povos é desenvolvido dentro do liberalismo político, sendo a extensão, a uma Sociedade dos Povos, da concepção liberal de justiça interna" pretende "desenvolver o Direito dos Povos dentro de uma concepção liberal da política exterior de um povo liberal razoavelmente justo" visando assegurar-se de que "os ideais e princípios da política exterior de um povo liberal também sejam razoáveis a partir de um decente ponto de vista não-liberal'

Rawls explica que quando utiliza a expressão Direito dos Povos "quero referir-me a uma concepção política particular de direito e justiça, que se aplicu aos princípios e normus do Direito e da prática internacionais" "Em referência a Sociedade dos Povos, explica Rawls que utilizará o termo para "designar todos os povos que seguem os ideais e os principios do Direito dos Povos nas suas relações mútuas" "

Utilizando o modelo da justiça como eqüidade desenvolvida em L'ma Teoria da Justiça. Rawls classifica cinco tipos de sociedades nacionais. incluidos em duas categorias de povos: A) Povos bem ordenados - 1) Povos liberuis razoáveis; e, 2) Povos decentes; B) Povos não bem ordenados - 3) Estados fora da lei. 4) Sociedades sob o ônus de condições desfavorávcis e, 5) Sociedades denominadas Absolutismos benevolcntes. ${ }^{5}$

Compreende Rawls que "o Direito dos povos sustenta que existem pontos de vista não-liberais e a questão do grau em que povos não-liberais devem ser tolerados é uma questão essencial de política externa liberal" 6

\section{Parte I A primeira parte da teoria ideal}

A primeira parte da tenria ideal expõe o Direito dos povos como parte do que ele denomina "utopia realista" Conforme Rawls, uma "filosofia politica é realisticamente utópica quando estende o que se pensa ordinariamente como os limites das possibilidades políticas práticas"

Analisando a sociedade liheral. no caso interno, denominadas de sociedade democrática constitucional razoavelmente justa, reconhece sete condições para que exista a utopia realista: 1) Valer-se de leis efetivas da natureza e alcançar o tipo

RAWLS. John. O Direito dos Povos. p. 3.

Id. Ibid., p. 3.

Id. Tbid., p. 4-5.

Id. Tbid.. p. 7-13. 
de estabilidade que essas leis permitam - é a estabilidade pelas razões certas (adota o pensamento de Rousseau, na abertura do Contrato Social); 2) Os primeiros princípios e preceitos devem ser funcionais e aplicáveis a arranjos políticos e sociais em andamento (aqui deverá ser utilizados o conceito de bens primários - direitos e liberdades básicas, oportunidades, renda e fortuna, e as bases sociais do respeito próprio); 3) A categoria do político deverá conter em si todos os elementos essenciais para uma concepção política de justiça (significa que a categoria do político não conterá uma doutrina abrangente); 4) Em razão do pluralismo razoável, a democracia constitucional deve ter instituições politicas e sociais que levem eficazmente seus cidadãos a adquirir esse sentido adequado de justiça à medida que crescem e participam da sociedade (exigência de senso de cooperação política, imparcialidade, tolerância e disposição para soluções de compromisso com os outros); 5) A estabilidade social deverá basear-se sobre a concepção política razoável de Direito e justiça. afirmada por um consenso sobreposto de doutrinas abrangentes; 6) A concepção política deve ter uma idéia razoável de tolerância ${ }^{7}$ dentro de si mesma, mostrando a razoabilidade da tolerância pela razão pública.

Esclarece Rawls que em uma família de concepções liherais razoáveis de justiça. haverá três princípios característicos que devem satisfazer o critério da reciprocidade. sendo que esse exige que "quando os termos são propostos como os mais razoáveis de cooperação imparcial, os que os propõem pensem que é, pelo menos, razoável para outros aceitá-los como cidadãos livres e iguais, não como dominados ou manipulados ou sob pressão causada por uma posição politica ou social inferior" " Portanto. ao longo do tempo a sociedade se torna um sistema imparcial de cooperação.

Rawls categoricamente acredita e defende a viabilidade da utopia realista e da existência de Sociedade dos Povos razoável, mesmo que tenham ocorrido Guerras de Religião e a Inquisição; e também o Holocausto. Portanto, "devemos sustentar e forlalecer a nossa esperança, desenvolvendo uma concepção razoável e funcional de

7 Na nota 8, Rawls resume os pontos principais dessa concepção de tolerância, conforme exposta no livro Liberalismo Politico. São elas: 1) Péssoas razoáveis não afirmam todas as mesmas doutrinas abrangentes: 2) São afirmadas muitas doutrinas razoáveis, das quais nem todas podem ser verdadeiras ou corretas, julgadas a partir de qualquer doutrina abrangente; 3) Não é irrazoável afirmar nenhuma das doutrinas abrangentes razoáveis; 4) Outros que afirmam doutrinas razoáveis diferentes das nossas também são razoáveis; 5) Ao afirmar a nossa crença em uma doưrına que reconhecemos como razoável, não estamos sendo irrazoáveis: 6) As pessoas razoáveis pensam que seria irrazuável usar o poder político. se o tivessem, para reprimir outras doutrinas que sejam razoaveis, mas diferentes da sua. RAWLS. John. $O$ Direito dos Povos. p. 22.

8 São as seguintes: a) o primeiro enumera os direitos e liberdades básicas, a partir de um regime constitucional; b) o segundo atribui a esses direitos. liberdades e oportunidades uma prioridade especial. especialınente no que diz respeito às exigências dos valores do bem geral e do perfeccionismo; e, c) o terceiro assegura a todos os cidadãos os bens primários necessários para capacita-los a fazer uso inteligente e eficaz das suas liberdades. RAWLS. Jonh. O Direito dos Poros, p. 19. 
direito político e justiça que se aplique às relações entre os povos (...) Prosseguir dessa maneira supõe a razoabilidade do liberalismo político, e desenvolver um Direito dos Povos razoável a partir do liberalismo politico confirma a sua razoabilidade. Esse Direito é sustentado pelos interesses fundamentais das democracias constitucionais e de outras sociedudes decentes" 9

Rawls expõe que escolheu o nome "povos" em vez de "nações" ou "Estados" porque "quis conceber os povos como tendo curacterísticus diferentes das que têm os Estados, sendo inadequada à idéia de Estados tal como tradicionalmente concebida, com os seus poderes de soberania" 10 Concebe a idéia de povos, com as características dos povos democráticos liberais (e povos decentes): 1) Governo constitucional razoavelmente justo, que servem os seus interesses fundamentais; 2) Cidadãos unidos pelo que Mill denominou "afinidades comuns" (que configuram a própria nacionalidade do povo, expressa na língua, na religião, nos limites geográficos. na história nacional e na identidade de raças); e. 3) Natureza moral. " Porém, as diferenças entre Estados e povos. fundamentam-se "em até que ponto a racionalidade, a preocupação com o poder e os interesses básicos são preenchidos" A diferença entre Estados e povos será enorme nas seguintes situações: 1) a rucionalidade ${ }^{12}$ exclui o razoável; 2) a preocupação com o poder é predominante de um Estado; 3) os interesses incluem conversão de outras sociedades à religião do Estado; 4) aumento do império e conquista territorial; 5) ganho de prestígio e glórias dinástica, imperial ou nacional; e 6) aumento de força econômica relativa. ${ }^{13}$ Além disso. a distinção fundamental entre povos e Estados é que "povos justos estão plenamente preparados para conceder justamente o mesmo respeito e o mesmo reconhecimento adequado a outros povos, como iguais" ${ }^{14}$ Significa que, na sua igualdade, os povos reconhecem e aceitam as desigualdades dos outros povos, oferecendo a esses outros povos termos justos de cooperação política e social.

9 RAWLS. John. O Direito dos Povos, cit. p. 30.

10 Id. Ibid., XVII.

11 A primeira característica $i$ institucional, a segunda é cultural e a terceira exige uma ligação firme com uma concepção politica (moral) de Direito c justiça. RAWLS, John. O Direito dos Povos, $30-31$.

12 O principio da racionalidade (racionality) invocado em Uma Tcoria da Justiça è o que usa habitualmente a teoria social - racional a ação através da qual um agente favorece seus próprios interesses. É racional que as partes "tratem de proteger as liberdades, ampliar as oportunidade e aumentar os meios para promover seus objetivos, quaisquer que sejam". Entretanto, Raw's introduz uma cláusula de desinteresse mútuo: em particular, as partes que se encontram na situação original não podem sentir-se invejas umas das outras. "A suposiçào especial que tenho é que a um individuo racional não lhe assalta a inveja". Equipada com uma teoria geral do bem e informada dos atos gerais da psicologia moral, as partes situadas na posição original podem tomar uma decisào racional.

13 RAWLS. John. O Lireilo dos Povos, cit,, p. 36-37.

it Id. Ibid., p. 45. 
Explica sobre as duas posições originais ${ }^{15}$ (posição original como modelo de representação - extensão da idéia do contrato social ao Direito dos Povos; e estender a idéia liberal ao Direito dos Povos). Ao iniciar a análise da posição original, enfatiza que esta ao ser observada com um véu de ignorância ${ }^{16}$ é um modelo de representação para as sociedades liberais e, "modela como condições justas e razoáveis para as partes, que são representantes racionais de cidadãos livres e iguais, razoáveis e racionais, para especificarem termos de cooperação para regulamentar a estrutura básica dessa sociedade" 17

Rawls identifica cinco características essenciais, ao analisar a posição original como modelo de representação: (1) a posição original modela as partes como representando os cidadãos imparcialmente; (2) ela modela como racionais, e (3) ela os modela selecionando, dentre princípios de justiça disponíveis, aqueles que se aplicam ao sujeito adequado - estrutura básica nesse caso; (4) as partes são modeladas como fazendo essas seleções pelas razões adequadas; e, (5) as partes são modeladas como selecionando por razões relacionadas com os interesses fundamentais dos cidadãos como razoáveis e racionais. Essas condições são satisfeitas quando os cidadãos realmente são representados imparcialmente (razoavelmente), em vista da simetria (ou da igualdade) da situação dos seus representantes na posição original. As partes também são modeladas como racionais, quando seu objetivo é fazer o melhor que podem pelos cidadãos cujos interesses básicos representam, conforme especificado pelos bens primários, que abrangem as necessidades básicas como cidadãos. ${ }^{18}$

A posição original deve ser entendida como aquela na qual as pessoas racionais realizam acordos eqüitativos sem vulnerar os elementos da estrutura básica. Para maiores explicações ver o Cap. III, do livro Uma Teoria da Justiça, de autoria de Rawls.

16 Seguindo o economista William Vickerey e a teoria dos jogos de John Hersany, Rawls apela a um instrumento analitico denominado "véu da ignorância" (Veil of ignorance). para caracterizar a ignorância parcial suposta dos agentes em uma situação de eleição de preferências (em uma Teoria da Justiça se trata da situaçăo original). Trata-se de um "experimento mental", puramente teórico, mediante o qual se procura impedir que os individuos busquem vantagens para si mesmos. Tal como o apresenta Raw/s no capitulo terceiro de uma Tcoria da Justiça: "(as partes) Não sabem como as diversas alternativas afetarão seus próprios casos particulares. vêem-se assim obrigadas a avaliar os principios unicamente sobre a base de considerações gerais" Imagine-se, pois, que situados sob o véu de ignorància, os indivíduos ignoram as caracteristicas de sua sociedade e circunstâncias tais como a situação econômica e social, a cultura, etc...; por ignorar, inclusive desconhecem a que classe social pertencem, sua boa ou má fortuna, seu sexo e suas aptidões naturais (inteligência, força,...). Os individuos ignorariam também qual é sua concepção de hem ou as particularidades do plano de vida que pretendem executar e suas caracteristicas psicológicas particulares. Pois bem, seria justa, segundo Rawls, aquela decisão que os individuos tomariam considerando a melhor para eles nas condições do "véu da ignorância" Essa teoria tem sido objeto de grandes controvérsias, pois na realidade social, os individuos nunca tomam suas decisões em circunstàncias nem sequer aproximadas ao do véu da ignorância, scnão sendo conscientes de suas condições particulares (nivel de renda, comunidade a que pertencem, etc...) e tentando maximilizá-las. RAWLS, John. ('ma Teoria da Justiça, cit., p. 146-153.

17 Id. Ibid., p. 39.

18 Id. Ibid., p. 40. 
Na segunda posição original (utilizada para estender uma concepção liberal ao Direito dos Povos - é exterior), modela em condições justas e razões adequadas, quais os Direitos dos Povos especificados pelos representantes racionais dos povos liberais, partindo como pressuposto hipotético de que as partes estão sob o véu da ignorância e os interesses estão expressos pelos princípios liberais de justiça para uma sociedade democrática. ${ }^{19}$

Oito são os princípios formulados por Rawls: 1) Os povos são livres e independentes. e a sua liberdade e independência devem ser respeitadas por outros povos; 2) Os povos devem observar tratados e compromissos; 3) Os povos são iguais e são patês em acordos que os obrigam; 4) Os povos sujeitam-se ao dever de nãointervenção; 5) Os povos têm o direito de autodefesa, mas nenhum direito de instigar a guerra por outras razões que não a autodefesa; 6) Os povos devem honrar os Direitos Humanos; 7) Os povos devem observar certas restrições especificadas na conduta da guerra; e, 8) Os povos têm o dever de assistir a outros povos vivendo sob condições desfavoráveis que os impeçam de ter um regime político e social justo ou decente. ${ }^{20}$ Rawls explica que esta lista é incompleta, mas que o importante é que "os povos bem ordenados livres e independentes estão prontos a reconhecer certos princípios básicos de justiça política como governando a sua conduta. Esses principios constituem a carta básica do Direito dos Povos". ${ }^{21}$

Argumenta Rawls, que esses princípios formularão diretrizes para estabelecer organizações cooperativas entre as partes que compõe uma Sociedade dos Povos, dentro de padrões de equidade e dispositivos para assistência mútua. Para Rawls, são três as organizações desse tipo: 1) uma estruturada para assegurar o comércio justo entre os povos - GATT; 2) uma organizada com um sistema bancário cooperativo pronto para permitir empréstimos -. Banco Mundial; e 3) uma organização estruturada para agir e equilibrar as partes que compõem uma Sociedade dos Povos (similar ao das Nações Unidas) denominada por Rawls como Confederação de Povos (não-Estados). ${ }^{22}$

No caso da organização comercial - para estabelecer um comércio mundial, entende Rawls que esta regulamentaria adequadamente a estrutura das transações comercial de maneira justa - com uma distribuição justa e eqüitativa. Assim haverá vantagens em estruturar um mercado comercial de competição livre, pois as nações maiores não formarão oligopólios e cartéis. Quanto ao Banco Central e uma Confederação de Povos servirão para estabelecer uma linha de igualdade básica, com a

\footnotetext{
19 RAWLS, John. O Direito dos Povos, cit., p. 4l-42.

20 Id. Ibid., p. 47-48.

21 Id. Ibid.. p. 48.

22 Id. Ibid., p. 54.
} 
criação de um fundo de contribuições (no qual cada Povo contribuirá mais ou menos conforme a sua capacidade de contribuir) para um banco cooperativo (juros adequados sendo devidos sobre os emprístimos) e também pagarão taxas maiores ou menores (adotar o mismo critério de capacidade contributiva de cada Povo). Tudo isso, deve satisfazer o critério de reciprocidade. ${ }^{23}$

Em relação à paz democrática, Rawls inicialmente estabelece que para esta ser mantida estabelecerá dois propósitos, levando em consideração os valores básicos da liberdade e igualdade. No primeiro momento dois tipos de estabilidade serão observados: a estabilidade pelas razões certas e a estabilidade como equilibrio de forças. E, em seguida, tem o dever de dar uma resposta ao realismo politico, como teoria da política internacional, para todos aqueles que dizem ser a idéia de uma utopia realista uma visão quixotesca. ${ }^{24}$

Para Rawls na idéia de paz democrática liberal encontram-se unidas duas concepções: 1) as instituições sociais podem ser revistas para tornar as pessoas mais satisfeitas $^{2 \varsigma}$ e felizes (pela democracia - mesmo com as desgraças inalteráveis e as causas remotas imutáveis tais como o destino e a vontade de Deus, há instituições políticas e sociais que podem ser mudadas pelo povo); e 2) o comércio tende a levar à paz (é a concepção de Montesquieu, encontrada no Espirito das Leis, representada na expressão moeur douces) ${ }^{20}$ Essas duas idéias unidas levam a compreensão que uma sociedade democrática constitucionalmente justa é uma sociedade que combina e ordena os dois valores básicos da liberdade e da igualdade em função dos três princípios característicos: 1) os dois primeiros especificam direitos, liberdade e oportunidades básicas e atribuem a essas liberdades uma prioridade característica de tal regime; e 2) o terceiro princípios é a garantia de meios suficientes a todos os propósitos para capacitar todos os cidadãos a fazer uso inteligente e eficaz das suas liberdades - significa que nesse caso o critério de reciprocidade deverá ser satisfeito. E. para isso há de requerer uma estrutura básica impeditiva de que as desigualdades sociais e econômicas se tornem excessivas. ${ }^{27}$

Concebe Rawls que para ser atingida a estabilidade da paz democrática, faz-se necessário: 1) Certa igualdade imparcial de oportunidade, especialmente na

\footnotetext{
23 RAWLS. John. O Direiro dos Povos, cil., p. 55-56.

$24 \quad$ Id. Ibid., p. 56.

25 Rawls utiliza os conceitos desenvolvidos por Raymond Aron no que se refere a povos satisfeitos e paz por satisfação (em oposiçào a 'paz por poder' ou 'paz por impotência').

26 Na conccpção de Saint-Just - formação da democracia do século XVIII: a ordem social não era mais vista como fixa: as instituiçōes politicas e sociais podiam ser revistas e reformadas para o propósito de tornar os povos mass felizes e satisfeitos. RAWLS. John. O Direito dos Povos. cil. p. 59-60.

27 IJ. Ibid., p. 63.
} 
educação; 2) Uma distribuição decente de renda e riqueza que satisfaça a terceira condição do liberalismo: devem ser garantidos a todos os cidadãos os meios para todos os propósitos, necessários para que tirem vantagem inteligente e eficaz das suas liberdades básicas; 3) A sociedade como empregador de última instância por meio do governo geral ou local ou de outras políticas sociais e econômicas; 4) Assistência médica básica assegurada para todos os cidadãos; e 5) Financiamento público das eleições e maneiras de assegurar a disponibilidade de informação pública em questões de política. ${ }^{28}$

Seu intuito é combater a injustiça política, causadora dos grandes males da história humana, que são, segundo Rawls "a guerra injusta e a opressão, a perseguição religiosa e a negação da liberdade de consciência, a fome e a pobreza, para não mencionar o genocidio e o assassinato em massa" ${ }^{29}$ Compreende Rawls que "as formas mais graves de injustiça politica são eliminadas por politicas sociais justas ${ }^{30}$ (ou, pelo menos, decentes) e instituições básicas justas (ou pelo menos, decentes), esses grandes males acabarão por desaparecer" " Rawls denomina "fato do pluralismo razoável"32 um elemento que possibilita a existência de uma Sociedade dos Povos razoavelmente justa. Formula a Sociedade dos Povos, com povos liberais (as democracias constitucionais liberais) e com povos decentes (hierarquias de consulta decente).

$\mathrm{Na}$ concepção rawlsaniana, povos decentes são aqueles que apesar de não garantirem amplos direitos aos seus cidadãos, asseguram a eles a justiça do bem comum, oferecendo o mínimo de respeito aos Direitos Humanos, e o mínimo de liberdade política na atribuição de cargos e de formação de grupos sociais representativos.

Assim, a tônica rawlsiana estará na constituição da Sociedade dos Povos razoavelmente justa como uma utopia realista, que representa um cenário ainda não existente, mas realizável no futuro, quando as diferenças de poder e de riqueza são resolvidas por todos os povos num sistema de cooperação mútua, em que o uso da guerra é rustrito e os povos bem ordenados têm o dever de assistir aos povos onerados

28 RAWLS, John. O Direiro dos Povos, cit, p. 64-66.

29 Id. Ibid., p.7-8.

30 Para Rawls as instituições básicas de uma sociedade são: a social (a familia), a econômica (o mercado) e a politica (Constituição - é a mais importante de todas as instituições básicas).

31 RAWLS, John. O Direito dos Povos, cil., p. 7.

32 É considerado um equivalente nào-transcendental (politico) do "fato da razão" kantiano. Para Rawls. de acordo com o Liberalismo Politico, o Pluralismo Razocivel. compreende que em uma sociedade de povos, existe pluralidade de diferentes culturas. tradições, línguas, costumes; concepções morais, sociais, econômicas, filosóficas e políticas. Mesmo assim, há possibilidade de uma convivéncia eqüitativa de cooperação, sob um regime constitucional capaz de conquistar o apoio e o consenso sobreposto (ovellupping consensus). Observa-sc que o pluralismo í o tema (problema) que mais preocupa Rawls, pelo fato de ser o elemento caracterizador das sociedades demucráticas. Em nota de rodapé. Rawls indica consultar seu Liberalisıno Politico, para ver a definição de pluralismo razoável. 
procurando fazer com que eles alcancem uma condição de justiça política razoável, também se tornando, então, povos bem ordenados.

\section{Parte II - A segunda parte da teoria ideal}

$\mathrm{Na}$ segunda parte da teoria ideal, examina a tolerância em relação aos povos não liberais, estendendo essa tolerância aos "povos hierárquicos decentes" isto é, aqueles países que vivem não em uma democracia, mas que são sociedades razoavelmente justas.

Rawls denomina as sociedades hierárquicas decentes em sociedades associativas na forma, posto que seus membros são vistos na vida pública como membros de grupos diferentes, e cada grupo é representado no sistema jurídico por um corpo numa hierarquia de consulta decente. Além disso, para que uma sociedade hierárquica decente seja membro de boa reputação de uma Sociedade dos Povos razoável, dois critérios deverão ser observados: 1) A sociedade não tem objetivos agressivos e reconhece que deve alcançar seus fins legítimos por meio da diplomacia, do comércio e de outros caminhos pacíficos; 2) Este critério tem três partes: a) o sistema de Direito de um povo hierárquico decente, esteja em conformidade com sua idéia de justiça do bem comum (o que assegura a todos os membros do povo os Direitos Humanos); b) o sistema de Direito de um povo decente deve ser tal que imponha deveres e obrigações morais (distintos dos Direitos Humanos bona fide a todas as pessoas dentro do respectivo território; e c) Deverá haver uma crença sincera e razoável, da parte dos juízes e outros funcionários que administram o sistema jurídico, de que a lei é realmente guiada por uma idéia de justiça do bem comum. ${ }^{33}$

Em relação à tolerância, Rawls compreende que essa deverá incluir além da abstenção de exercer sanções políticas - militares, econômicas ou diplomáticas; mas também reconhecer as sociedades não-liberais como "membros participantes iguais, de hoa reputação, na Sociedade dos Povos, com certos direitos e obrigações, inclusive o dever de civilidade, exigindo que ofereçam a outros povos razões para os seus atos adequadas à Sociedade dos Povos" "i4

Expõe sobre os Direitos Humanos, procurando identificar os Direitos Humanos fundamentais como a "norma mínima" das instituições políticas, aplicável a todos os Estados que integram uma sociedade dos povos politicamente justa. Para Rawls, entre os Direitos Humanos encontra-se: 1) o direito à vida (aos meios de subsistência e segurança); 2) À liberdade (à liberação de escravidão, servidão e ocupação

3 RAWLS. John. O Direilo dos Povos, cit., p. 83-88.

it Id. ibid., p. 77. 
forçada e a uma medida de liberdade de consciência suficiente para assegurar a liberdade de religião e pensamento); 3) Ȧ propriedade (propriedade pessoal); e 4) à igualdade formal como expressa pelas regras da justiça natural (isto é, que casos similares devem ser tratados de maneira similar). ${ }^{35}$ Esse conjunto de direitos tem um estatuto especial no Direito interno das nações, sendo exigência básica para que um Estado possa integrar a comunidade internacional.

Os Direitos Humanos, para Rawls, diferenciam-se. assim, das garantias constitucionais ou dos direitos da cidadania democrática, e exercem três papéis relevantes: em primeiro lugar, a observância dos Direitos Humanos representa a condição necessária para que seja legitimado um regime político e aceita a sua ordem jurídica; o respeito aos Direitos Humanos, no Direito interno das nações, representa para Rawls, condição suficiente para que se exclua a intervenção em assuntos internos de outras nações, por meio, por exemplo, de sanções econômicas ou pelo uso da força militar; por fim, Rawls sustenta que os Direitos Humanos estabelecem um limite último ao pluralismo entre os povos. ${ }^{36}$

Os Direitos Humanos, no pensamento rawlsiano, expressam-se. portanto, através de normas jurídicas e políticas, que se referem ao mundo das relações entre as nações, expressando compromissos nacionais com valores, destinados a estabelecer uma ordem internacional politicamente justa.

Trata-se, em outras palavras. da remissão dos Direitos Humanos ao plano das relações entre os Estados que. para se legitimarem na comunidade internacional. devem ter como fundamento dos respectivos direitos internos o respeito à norma mínima internacional. Rawls procura estabelecer uma norma comum, um Direito cosmopolita que servirá como critério universal para o reconhecimento dos sistemas políticos e jurídicos nacionais. No debate sobre a intervenção em outros países, o tema tradicional da guerra justa será substituído pela análise da obediência dos estados a essa moralia minima internacional, que deverá estar expressa no texto e na prática constitucional. Nas palavras de Rawls "o que chamo de Direitos Humanos é um subconjunto adequado de direitos possuidos pelos cidadãos em um regime democrático constitucional liberal ou dos direitos dos membros de uma sociedade hierárquica decente" 37

Também procura demonstrar que é possível existir povos não-liberais que aceitam e seguem o Direito dos Povos, dando como exemplo um povo muçulmano não-

3s RAWL, John. O Direito dos Povos, cil., p. 85.

36 ld. Ibid., p. 104-105.

$\therefore$ Id. Ibid., p. 106. É importantu frisar que neste contexto, os Direitos Humanos na concepção rawlseniana são proclamados nos tratados internacionais. E, no caso do Brasil, conforme o art. $5^{\circ}, \S 2^{\circ}$, são incorporadus na constituição federal, ganhando stalus de norma constitucional. 
liberal (imaginário) denominado Casanistão, denominado por Rawls como um povo hierarquicamente decente.

Rawls explica que o Casanistão identifica-se por ser um povo islâmico, e que somente os mulçumanos podem influenciar nas decisões políticas mais importantes e ocupar posições superiores de autoridade política. Mas, há uma hierarquia de consulta decente, pois preenchem seis diretrizes: 1) garantem que todos os grupos devem ser consultados (todos os grupos podem expressar seus contentamentos e descontentamentos); 2) as pessoas pertencentes a um povo específico pertencem também a um grupo específico; 3 ) cada grupo específico tem uma representação em um corpo de representante, que deverá conter no mínimo algumas pessoas que conheçam e compartilhem os interesses fundamentais do grupo; 4) o corpo que toma a decisão final (composto pelos governantes) deve ponderar sobre os pontos de vista de cada grupo de acordo com as suas reivindicações, e os juízes e outros funcionários devem explicar e justificar a decisão dos governantes caso sejam convocados a fazê-lo; 5) a decisão final sobre as consultas deverá obedecer e estabelecer uma concepção daquilo que são prioridades especiais para o Casanistão; 6) Essas prioridades especiais deverão ser ajustadas como um sistema geral de cooperação e que os termos justos advindos do processo de consulta devem ser publicamente reconhecidos e respeitados; e 7) A existência de uma assembléia onde os grupos, ou seus representantes, possam se encontrar para tratar das questões políticas eventualmente pertinentes à vida de sua sociedade (mesmo que não seja em caráter decisório). ${ }^{38}$

\section{Parte III - a teoria não-ideal}

Na parte III, reflete sobre o plano da teoria não-ideal. Distinguindo-a em dois tipos: 1) Condições de não aquiescência (são as condições em que certos regimes recusam-se a aquiescer a um Direito dos Povos razoáveis - Estados fora da lei); e 2) Condições desfavoráveis (as condições de sociedades cujas circunstâncias históricas, sociais e culturais tornam difícil, se não impossível, alcançar um regime bem ordenado, liberal ou decente). Explica sobre a doutrina da guerra justa, das "sociedades sobrecarregadas" (corrupção) e o significado de justiça distributiva entre os povos. Para que os objetivos do Direito dos Povos sejam plenamente alcançados, as sociedades devem estabelecer um regime liberal ou decente.

Rawls não pode deixar de refletir sobre os três problemas imediatos da política externa contemporânea: A guerra injusta, a imigração e as armas nucleares, além

is RAWLS, John. O Direiro dos Povos, cit., p. 98-102. 
de outras armas de destruição em massa. No primeiro caso - o problema da guerra admite somente nos casos de autodefesa ou em casos graves de intervenção em sociedades injustas para proteger os Direitos Humanos ${ }^{39} \ldots$ é o direito à guerra dos povos bem ordenados. ${ }^{10}$

Ao justificar a doutrina da guerra justa pelos povos bem ordenados, expõe seis princípios que devem ser observados, posto que restringem a conduta de guerra jus in bello: 1) o objetivo de uma guerra justa é obter uma paz justa e duradoura entre os povos: 2) a guerra não deve ser contra Estados não-bem ordenados, cujos objetivos expansionistas ameacem a segurança e as instituições livres de regimes bem ordenados e ocasionem a guerra; 3 ) três grupos devem ser distinguidos: os lideres e funcionários do Estado fora da lei, os seus soldados, e a sua população civil ${ }^{41}$; 4) Os Direitos Humanos dos membros do outro lado, civis e soldados devem ser respeitados pelos povos bem $\operatorname{ordenados}^{42}: 5$ ) Os objetivos dos povos bem ordenados são demonstrados, conforme a guerra é travada e os pelos atos cometidos durante ela; bem como é importante o tipo de paz. e relações que é buscado; e 6) O raciocínio prático dos meios e fins devem sempre ter um papel restrito quando é julgada a adequação de uma ação ou de política. ${ }^{43}$

As sociedades oneradas, que são o segundo tipo de teoria não-ideal, carecem de tradições políticas e culturais, de capital humano e conhecimento técnico e. muitas vezes, dos recursos materiais e tecnológicos necessários para que sejam bem ordenadas. O objetivo de longo prazo das sociedades (relativamente) bem ordenadas ${ }^{44}$

39 "Quando uma socicdade liberal guerreia em autodefesa, ela o faz para proteger c preservar as liberdades básicas dos seus cidadãos e das suas instituições políticas constitucionalmente democráticas. Na verdade, uma sociedade liberal não pode exigir com justiça que os seus cidadãos lutem para conquistar riqueza económica ou obter reservas naturais, muito menos conquistar poder e império. (Quando uma sociedade persegue esses interesses ela já não honra o Direito dos Povos e toma-se um Estado fora da lei). Violar a liberdade dos cidadãos pela conșcrição ou outras práticas semelhantes na formação de forças armadas só pode ser feito, isto é, como necessário para defender as instituiçõcs democráticas liberais, as muitas tradiçōes religiosas e não-religiosas, e as formas de vida da sociedade liberal" RAWLS. John. O direiro dos povos, p. 120.

ii Neste ponto devemos refletir sobre os últimos acontecimentos envolvendo Fstados classificados por Rawls como povos liberais razoáveis bem ordenados (exemplifico com os Estados L'nidos da América e Inglaterra), que alegaram as razōes descritas na nota 8, para invadir o Afeganistão e o Iraque. F agora, nãodescartam a possibilidade de invasão ao Irã.

$\therefore$ Os lideres e funcionários do Estado fora da lei são responsávcis c desejaram a guerra, se portaram de modo criminoso - são criminosos. Os seus soldados. exceto os altos oficiais, não são responsáveis, pois estavam apenas cumprindo ordens. E. os membros da população civil, não podem ser responsabilizados, pois não que organizaram e provocaram a guerra, sendo que foram muitas vczes mantidos na ignorância. RAWLS, John. O Direilo dos Povos, cit., p.123-125.

12 Deve ser feito como medida educativa - visando unsinar aos soldados e civis inimigos o conteúdo, o significado e a importância dos Direitos Humanos. RAWLS, John. O Direilo dos Povos, p. 126.

4) O raciocínio deve ser estruturado e limitado pelos princípios e suposições precedentes. O raciocinio será guiado pela análise de custo-beneficio, do peso dos intcresses nacionais. e outras maneiras possiveis. Id. Ibid.. p. 127. 
deve ser o de trazer as sociedades oneradas, tal como os Estados fora da lei, para a sociedade dos povos bem ordenados. ${ }^{45}$

Rawls explica que é objetivo das sociedades bem ordenadas trazer os Estados fora da lei e as sociedades oneradas para a sociedade dos povos bem ordenados. No caso das sociedades oneradas, haverá o dever de assistência pelos povos bem ordenados.

O dever de assistência deverá observar três diretrizes, que são as seguintes: 1) Considerar que uma sociedade bem ordenada não precisa ser necessariamente rica, mas estabelecer uma poupança justa. concretizando e preservando instituições justas; ${ }^{46}$ 2) Perceber que a cultura política de uma sociedade onerada é muito importante e que há elementos que diferenciam as sociedades ... a cultura política, as virtudes políticas, a sociedade cívica, a probidade e a indústria dos seus membros (cidadãos), capacidade de inovação, reflexões acerca de sua política demográfica, e outros elementos mais; ${ }^{47}$ e 3 ) Ajudar as sociedades oneradas a serem capazes de gerir seus próprios negócios, de modo razoável e racional, e, assim, tornarem-se membros da sociedade dos povos bem ordenados - finaliza o dever de assistência, mesmo que as sociedades, agora bem ordenadas, continuem relativamente pobres, posto que não é dever das sociedades bem ordenadas agirem de maneira paternalista. ${ }^{48}$

Em relação ao problema da migração. Rawls sustenta que o governo tem um papel importante: ser agente eficaz de um povo que assume a responsabilidade pelo seu território e pelo tamanho da sua população. Enumera algumas causas de migração, tais como: 1) Perseguição de minorias religiosas e étnicas, a negação dos Direitos

$\therefore$ Rawls denominada sociedade bem ordenada (Well-ordered society) uma associação de pessoas organizadas de maneira que favoreçam os interesses de seus membros, regulada por uma concepção pública de justiça, que se aplica de uma maneira efetiva. ('onforme Rawls: "Uma sociedade está bem ordenada não-somente quando está desenhada para promover o bem de seus membros, senão quando está efetivamente regulada por uma concepção de justiça. Isto que dizer que se trata de uma sociedade em que: I. Cada qual aceita e sabe que os outros aceitam os mesmos principios de justiça; e, 2. As instituições sociais básicas satisfazem geralmente estes principios e se sabe geralmente o que fazem" O primeiro principio de uma sociedade bem ordenada $\dot{i}$, de certa maneira. banal - recuperar a idéia já presente no apóstolo Marcos. segundo o qual a lei foi feita para os homens e não para subordiná-los enquanto que o segundo, que é kantiano, exige a publicidade e a reciprocidade. De certa maneira, todo o propósito de Rawls é oferecer uma sintese de ambos elementos.

t5 RAWLS, John. O Direito dos Povos, cit., p. 139.

46 Para Rawls o propósito de uma poupança justa "é estabelecer instituiçôcs básicas (razoavelmente) justas para uma sociedade democrática livre e assegurar um mundo social que torne possivel uma vida digna para todos os seus cidadãos"; e, portanto. "a poupança pode parar assim que as instituiçôes básicas justas (ou decentes) tenham sido estabelecidas; bem como "a grande riqueza não é necessariamente para estabelecer instituições justas (ou decentes). Id. Ibid.. p. 140.

47 Id. ibid.. p. 142.

48 Id. Ibid., p. 146. 
Humanos; 2) Opressão política de várias formas; 3) fuga de fome; e 4) Pressão populacional no território de origem - desigualdade e a sujeição das mulheres. ${ }^{49}$

É importante frisar que ao explicar quais deveriam ser as medidas tomadas para combater a fome e a pressão populacional, Rawls faz referência ao trabalho de Amartya Sen e seu estudo empírico de quatro casos históricos (Bengala, Etiópia, Sahel, Bangladesh) no qual explica que o problema da fome não são apenas crises de alimento, mas que são "atrihuiveis a falhas na estrutura politica e social e ao fracasso em instituir políticas para remediar os efeitos de quedas na produção de alimentos" $5 n$

Em relação à pressão populacional. Rawls sustenta que um fator decisivo para que a taxa de natalidade diminua é o respeito à condição da mulher, posto que ao permitir que as mulheres participem do processo político (votar e participar da política), receba educação e a utilizem para possuir e gerir riquezas e propriedades; a taxa de natalidade comprovadamente cairá em poucos anos. ${ }^{51}$

Rawls analisa a justiça distributiva entre os povos - princípios de justiça, considerando-o importante para esclarecer o dever de assistência. Explica que são três as razões para se preocupar com a desigualdade na sociedade nacional e como aplicá-las à Sociedade dos Povos, quais sejam: 1) Reduzir as desigualdades é aliviar o sofrimento e as dificuldades dos pobres (não-significa igualdade de riquezas entre os membros da sociedade); 2) A distância entre ricos e pobres leva a estigmatização de alguns cidadãos e a uma desigualdade de tratamento - esses cidadãos passam a ser vistos como inferiores e são marginalizados (devem ser evitados os estabelecimentos de convenções que reconhecem hierarquias sociais mediante expressões de deferência); e 3) A eqüidade tem um importante papel no processo político da estrutura da Sociedade dos Povos, posto que assegura a honestidade das eleições e das oportunidades políticas de concorrer a cargo público - igualdade de oportunidades significa que as condições sociais dadas são tais, que independente de sua classe social ou origem, todos os cidadãos terão a mesma chance de alcançar uma situação social favorecida, lhes sendo assegurada educação imparcial para eliminar a discriminação. ${ }^{52}$

Rawls discorda da posição de Beizt, quanto aos dois princípios distinguidos por este, que são: princípio de redistribuição de recursos (que visa ajudar os paises pobres em recursos naturais com produção autárquica) e princípio de distribuição global (que funcionaria de forma análoga ao princípio usado no caso

49 Compreende Rawls que periodos prolongados de fome. são causados, em grande parte. por omissões políticas e pela ausência de govemo dicente.

so RAWLS, John. O Direito dos Povos, cit., p. 143.

s) Id. Ibid., p. 144.

52 Id. Ibid., p. 14\%-151. 
nacional em Uma teoria da justiça). Para Beizt os países são mais ricos por que possuem maiores recursos disponíveis, e, portanto têm um melhor desempenho. Rawls acredita que esse desempenho é em função da sua cultura política - as virtudes política e cívicas dos seus membros, não o nível dos seus recursos, posto que a arbitrariedade da distribuição de recursos naturais não causa nenhuma dificuldade. ${ }^{53}$

Para comprovar sua posição considera dois casos ilustrativos: (Caso 1) países liberais ou decentes com mesmo nível de riqueza - $\mathrm{O}$ primeiro industrializa-se e aumenta a taxa de poupança (real), enquanto o segundo mantém sua estrutura agropastoril, preferindo reafirmar seus valores sociais. Após uma década, o primeiro país obtém duas vezes mais riqueza que o segundo; (Caso 2) $O$ índice de crescimento populacional elevado em dois países liberais ou decentes, que provêm os elementos de justiça igual para as mulheres - O primeiro país enfatiza esses elementos e as mulheres prosperam no mundo político e econômico, o que leva a um crescimento populacional zero, permitindo um nível crescente de riqueza ao longo do tempo. Enquanto o segundo, por causa de questões e valores religiosos e sociais vigentes, não reduz sua taxa de crescimento populacional e esta permanece razoavelmente elevado. Após algumas décadas, a primeira sociedade estará duas vezes mais rica que a segunda. Rawls não considera justo que no primeiro caso o país industrializado seja taxado para dar fundos ao segundo, haja vista que as sociedades escolheram os seus caminhos. Também usa os argumentos de que os povos são livres e responsáveis, capazes de tomar suas próprias decisões; portanto, não é justo que seja instituída taxa para a primeira sociedade, agora mais rica. ${ }^{54}$

Rawls observa que a diferença entre um principio igualitário global e o dever de assistência, é baseada nas seguintes proposituras: o princípio igualitário global tem por objetivo ajudar os pobres em todo o mundo propondo um Dividendo Geral de Recursos (DGR) a ser pago por toda sociedade a um fundo internacional administrado com esse propósito. Enquanto que o dever de assistência busca elevar os pobres do mundo até que sejam cidadãos livres e iguais de uma sociedade razoavelmente liberal ou membros de uma sociedade hierárquica decente, havendo deliberadamente um ponto de interrupção, quando o objetivo proposto é atingido. ${ }^{55}$

Rawls finaliza o capitulo, colocando em contraste uma visão cosmopolita com o Direito dos Povos. Observa que este último supõe que cada sociedade tem na sua população cabedal suficiente de capacidades humanas, dispondo de recursos humanos potenciais para concretizar suas instituições justas. com fim político de tornar-se

3 RAWLS, John.O Direito dos Povos, cit.. p. 153.

is Id. Ibid., p. 154.

55 Id. Ibid.. p. 155-156. 
plenamente justa e estável pelas razões certas. No momento que este fím é alcançado, não há prescrição de nenhum outro alvo. A visão cosmopolita tem como interesse final o bem-estar dos indivíduos (com o determinar se há possibilidade de melhorar o bem-estar da pessoa globalmente em pior situação). ${ }^{56}$

\section{Parte IV - Conclusão}

$\mathrm{Na}$ conclusão, compondo a parte IV da obra, reflete sobre a razão pública e o Direto dos Povos; bem como sobre a possível reconciliação em nosso mundo.

Compreende que a concepção de razão pública" integra "o Direito dos Povos, que estende a idéia de um contrato social à Sociedade dos Povos e revela os princípios gerais que podem e devem ser aceitus por sociedades liberais e não-liberais (mas decentes) como padrão para regulamentar o seu comportamento perante outras"

Por fim, nos diz que: "Se não for possivel uma Sociedade dos Povos razoavelmente justa, cujos membros subordinam os seus poder a objetivos razoáveis, $e$ se os seres humanos forme, em hoa parte, amorais, quando não incuravelmente descrentes e egoístas, poderemos perguntar; como Kant, se vale a pena os seres humanos viverem na terra" 58

São Paulo, novembro de 2006.

56 RAWLS, John. O Direito dos Povos, cit., p. 157.

57 Para Ralws a idéia de razão pública tem cinco aspectos diferentes: I) As questōes politicas fundamentais às quais se aplica: 2) As pessoas a quem se aplicam (funcionários do governo e candidatos a cargo público); 3) seu conteudo como dado por uma lamília de concepções políticas razoáveis de justiça; 4) A aplicação dessas concep̧̧ōes em discussões de normas coercítivas; e. 5) A verificação pelos cidadàos de que os princípios derivados das suas concepções de justiça satisfazem o critério de reciprocidade. Além disso, a razão é pública. porque: a) é a razão de cidadãos livres e iguais; b) seu tema é o bem público no que diz respeito a questōes de justiça politica fundamental, cujas questôes são elementos constitucionais essenciais e de justiça básica; e, c) a sua natureza e conteúdo são públicos, sendo expressos no raciocinio público por uma familia de concepções razoáveis de justiça política que se pense que possa satisfazer o critério de reciprocidade. Id. Ibid.. p. 175-176.

Id. Ibid., p. 169. 


\section{Referências}

ARAÚJO, Cícero. Legitimidade, Justiça e Democracia: O legado de John Rawls. Lua Nova, n. 57, 2002.

. República e Democracia. Lua Nova, n. 51. 2000.

ARISTÓTELES. Política. 2. ed. Brasília: UnB, 1988.

ARON, Raymond. Paz e Guerra entre as Nações. Brasília: UnB, 1979.

BAYNES, Kenneth. The Normative Grounds of Social Criticism: Kant, Rawls, Habermas. Albany: SUNY Press, 1992.

BEITZ, Charles. International Ethics. Nova Jersey: Princeton University Press, 1985.

Political Theory and International Relation. Princeton (New Jersey): Princeton University Press, 1979.

. International Liberalism and Distributive Justice. World Politics, v. 51, n. 2, 1999.

Liberalismo Internacional e Justiça Distributiva. Lua Nova, n. 47, 1999.

BLOCKER, H. Gene; SMITH, Elizabeth H. (Orgs.). John Rawl's theory of social justice: an introduction. Athens: Ohio University Press, 1980.

BROWN, Chris. John Rawls, "The Law of Peoples", and International Political Theory. Ethics and International Affairs, v. 14, 2000.

The construction of a realistic utopia: John Rawls and international political theory. Review of International Studies, n. 28, 2002.

BUCHANAN, Allen. Rawls's Law of Peoples: rules for a vanished westphalian world. Ethics, v. 110. ก. 4. 2000.

CABRERA, Luis. Toleration and tyranny in Rawls's Law of Peoples. Polity, winter, 2001.

DANIFLS, Norman (Org.). Reading Rawls. Oxford: Blackwell, 1975.

DAVION, Victoria; WOLF, Clark (Orgs.). The idea of a political liberalism: essays on Rawls. Lanham e Oxford : Rowman \& Littlefield Publishers, 2000.

DOMBROWIKI. Daniel A. Ruwls and religion: the case for political liberalism. Albany: State University of New York Press, 2001. 
FREEMAN, Samuel (Org.). The Cambridge Companion to Rawls. Cambridge University Press, 2003.

GIANNOTTI. José Arthur. Contrato e Contrato Social. Filosofia Política, n. 6, p.9-29, 1999.

GUILLARME, Bertrand. Rawls et l'égalité démocratique. Paris: Presses Universitaires de France, 1999.

HÖFFE, Otfried. Justiça Politica: Fundamentação de uma Filosofia Crítica do Direito e do Estado. Petrópolis: Vozes, 1991.

KANT, Immanuel. Critica da Razão Pura. São Paulo: Nova Cultural. 1999.

KRISCHKE, Paulo J. A Cultura Política Pública em John Rawls: Contribuições e Desafios à Democratização. Revista de Filosofia Politica - Nova Série, n. 2, p. 85-97, 19.98

KUKATHAS, Chandran; PETTIT, Philip. Rawls: A Theory of Justice and its critics. Oxford: Polity, 1990.

KUPER, Andrew. Rawlsian Global Justice Beyond The Law of Peoples to a Cosmopolitan Law of Persons. Political Theory. v. 28, n. 5, October 2000.

LANDRIĖRE, Jean; VAN PARIJS, Philippe (Orgs.). Fondements d'une théorie de la justice: essais critiques sur la philosophie politique de John Rawls. Louvain-la-Neuve: Libr. Peeters, 1984.

MARTIN, Rex. Rawls and rights. Lawrence: University Press of Kansas, 1985.

MCCARTHY, Thomas. Kantian Constructivism and Reconstructivism: Rawls and Habermas in Dialogue, Ethics, n. 105, p.44-63, 1994

MICHELMAN, Frank. Welfare Rights in a Constitutional Democracy. Washington University Law Quarterly, p. 680-685, summer 1979.

MUNOZ-DARDÉ, Véronique. La justice sociale: Le libéralisme égalitaire de John Rawls. Paris: Nathan, 2000.

NEDEL, José. A teoria ético-política de John Rawls. Porto Alegre: Edipucrs, 2000.

NOZICK, Robert. Anarquia, Estado e Utopia. Rio de Janeiro: Jorge Zahar, 1994.

OLIVEIRA, Nythamar de.Tractatus ethico-politicus. Porto Alegre: Edipucrs, 1999. ('aps. 3 e 7. Rawls. Rio de Janeiro: Zahar. 2003.

Kant, Rawls e a fundamentação de uma tcoria da justiça. Justiça e Eqüidade, Florianópolis: Insular, 1998. 
Kant como Árbitro entre Hobbes e Rawls. Filosofia Politica, n. 4, p.34-53, 1999.

. Critique of public reason revisited: Kant as Arbiter between Rawls and Habermas, Veritas. n. $45 / 4$, p. 583-606, 2000 .

Justiça e tolerância segundo Rawls. In: OLIVEIRA, Nythamar Fernandes de; SOUZA, Draiton Gonzaga de (Orgs.). Justiça e Politica: Homenagem a Otfried Höffe. Porto Alegre: Edipucrs, 2003. p. 431-450.

Les défis normatifs de la justice globale selon John Rawls. In: MATTÉI, Jean-François; ROSENFIELD; Denis (Eds.). Civilisation et Barbarie. Paris: PUF, 2002. p. 211-229.

. Teoria ideal e teoria não-ideal em Platão, Kant e Rawls. In: NAPOLl. Ricardo B. di: ROSSATTO, M. Fabri e N. (Orgs.). Ética e Justiça. Santa Maria: Editora da UFSM/Palotti, 2003. p. $95-116$.

- Globalization and democratization in Brazil: an interpretation of Rawls's Political Liberalism. In: PUNZI, A. (Ed.). Omaggio a John Rawls. Quaderni della Rivista Internazzionale di Filosofia del Diritto, v. 4. Milano: Giuffrè, 2004. p. 565-586.

POGGE, Thomas W. Realizing Rawls. Ithaca: Cornell, 1989.

RAWLS, John. O Direito dos povos. Tradução Luis Carlos Borges. São Paulo: Martins Fontes, 2004.

RAWLS, John. Uma teoria da justiça. Tradução Almiro Pisetta e Lenira M. R. Esteves. São Paulo: Martins Fontes, 1997.

O Liberalismo Politico. Tradução Dinah de Abreu Azevedo. São Paulo: Ática, 2000.

Constitucional liberty and the concepts of justice. In: FREEMAN, S. (Ed.). Collected Papers. Cambridge: Harvard Universit Press, 1999.

. Kantian constructivism in moral theory. Harvard Universit Press. 1989.

RIC.HARDSON, Henry S. (Org.) Development and main outlines In: Rawls's theory of justice. New York: Garland, 1999.

SEN, Amartya. Poverty and famines: an essay on entitlement and deprivation. Oxford: Clarendon Press, 1981.

SIMPLICIO, Juan. La justicia segun Rawls. Disponivel em: <http://www.aunque.com.es>. 2003.

TAN, Kok-Chor. Toleration, Diversity, and Global Justice. Penn State Press, 2001. 
VAN PARIJS, Philippe. O que é uma sociedade justa? Tradução Cintia A. de Carvalho. São Paulo: Ática, 1997.

VECCHIO. Giorgio del. Lições de filosofia do direito.5.ed. Lisboa: Armédio Amado, 1979.

VITA. Alváro de. A justiça igualitária e seus críticos. São Paulo: Ed. Unesp, 2000.

. A tarefa prática da filosofia política em John Rawls. Lua Nova, n. 25, p. 5-24, 1992. 